\title{
SIGNAL-ORIENTED RAILROAD SIMULATION
}

\author{
Marcelo Moretti Fioroni \\ Johanna Gomez Quevedo \\ Isac Reis Santana \\ Luiz Augusto G. Franzese \\ Paragon Decision Science \\ Rua Arminda, $93-5^{\text {th }}$ floor \\ 04545-100, São Paulo, BRAZIL
}

\author{
Daniel Cuervo \\ Paola Sanchez \\ Francesco Narducci \\ Carbones del Cerrejón \\ Calle 100 No. 19-54 \\ Bogota, COLOMBIA
}

\begin{abstract}
Railroad simulation is always challenging to modelers, since this kind of system has physical restrictions that cannot be ignored or deeply simplified without losing precision. The great difficulty on modeling the railroad behavior lies on the train movement, specially on single lines. This paper describes the experience of modeling a railway line used for coal transportation in Colombia, used by one of the largest openpit coal mining companies in the world, and the most important in the country: Carbones del Cerrejón. After experiencing and analyzing different options, the model was built with a signal-oriented decision process, where all train movements are allowed or restricted by the line signals. This approach made possible to represent every specific decision regarding the train movements in different sections of the line, using a simple local, instead of a global complex intelligence. It has proven to be very precise, fitting the real system with small error, and allowed several experiments to support decisions at Cerrejón.
\end{abstract}

\section{INTRODUCTION}

Railroad simulation has proven to have significant benefits for countries and companies, as it is a quick and economical way to test various scenarios, and to support decision making processes without having to make large structural investments. At the same time, railroad simulations have proven to be challenging for modelers and the particularities of each system add up to the modeling complexity. Basically, the challenge on simulating single railroad lines is the same of the real system: avoid collisions, blockages and delays while respecting the traffic rules.

Being challenging but valuable tools, academics and professionals have put a lot of effort to study railroad modeling as exemplified by the studies of Dessouky, Lu, and Leachman (2002), Krueger et al. (2000), and Leilich (1998). This last study highlights the importance of choosing the most adequate simulation approach, and presents some examples and cases regarding capacity. According to Leilich (1998), a railroad capacity study must have its focus on finding an infrastructure configuration that combines the best traffic flow and the lowest investment, as a result of comparing two or more investment options, such as double track or new sidings.

Passenger transportation studies usually concentrate on punctuality on short distance networks, as presented by Hooghiemstra and Teunisse (1998). Cargo transportation railroads studies usually focus on capacity issues. Due to the large distances and railway costs, cargo lines are usually single, with a set of crossing sidings to enable the trains to flow in both directions. In rare cases, where the traffic is too heavy, there are long double track lines, like in the case described by Franzese, Fioroni, and Botter (2003). 
These case were about a Brazilian rail line dedicated to iron ore transportation, but the case of study presented in this paper, deals with a single line coal cargo transportation railroad. It describes a new approach for representing a railroad line, developed during a study for the mining company Carbones del Cerrejón.

Cerrejón is an integrated mining and transport complex in La Guajira, a department in the northernmost section of Colombia, as shown in Figure 1. The company employs more than 10 thousand people, and is the biggest private exporter of Colombia. It is independently operated, but belongs in three equal parts to subsidiaries of BHP Billiton, Anglo American, and Xstrata.

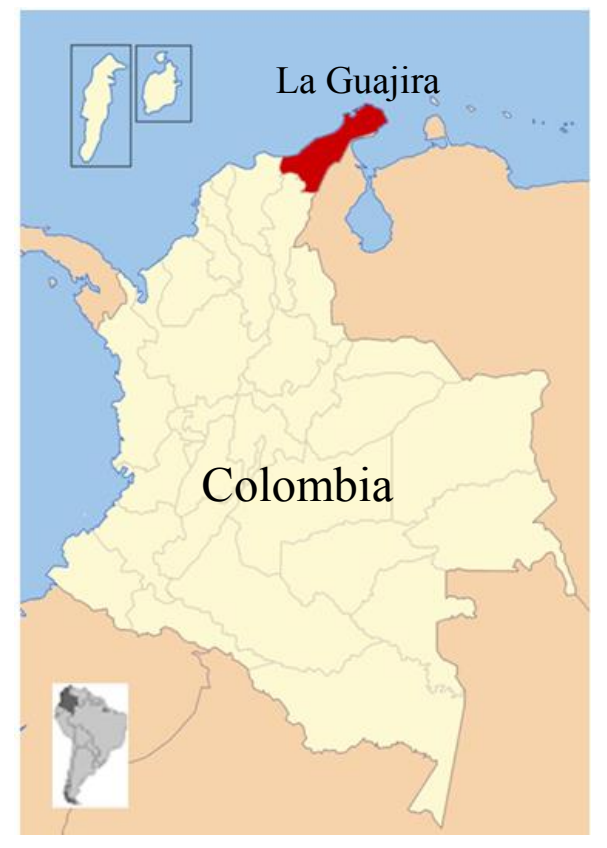

Figure 1: Cerrejón's location in La Guajira, Colombia.

Cerrejon's operation is mainly divided into three processes: a thermal coal open-pit mine that produces more than 32 million tons per year (Mtpy), a railroad that is 150 kilometers long, which is the main subject of this study, and a maritime port that receives ships of up to 180,000 tons dead weight.

In 2010, Cerrejon started working on pre-feasibility and feasibility studies to expand its operation from 32 Mtpy to 40 Mtpy. For the expansion studies, simulation models were used to determine the system's bottlenecks and the required investments to reach the expected coal chain capacity. The expansion to 40 Mtpy was approved by Cerrejon's shareholders in 2011.

This paper describes the problem faced to simulate the Cerrejón's railroad, listing the railroad situations that can be treated in a way that might be similar to many other railroads. After that, the signaloriented algorithm is described, explaining how it solves all situations. In the following, the model is presented, showing how it was implemented and finally, results are presented and a conclusion is given.

\section{THE PROBLEM}

A railroad network has several traffic rules to avoid the situations shown on Figure 2 below. The situation "a", frontal collision, may happen on a single line, since trains in opposite directions have to share the same line. The "b" situation, rear collision, may happen in a single line and also in a double line, if a faster train approaches a slower one. The "c" situation, deadlock, may happen in single lines that allow the train to stop on the line. 
All those cases are usually avoided because there are a CTC (centralized traffic control) which monitors every train and gives them movement instructions. Also, the automated signaling may help the train to prevent most problems.
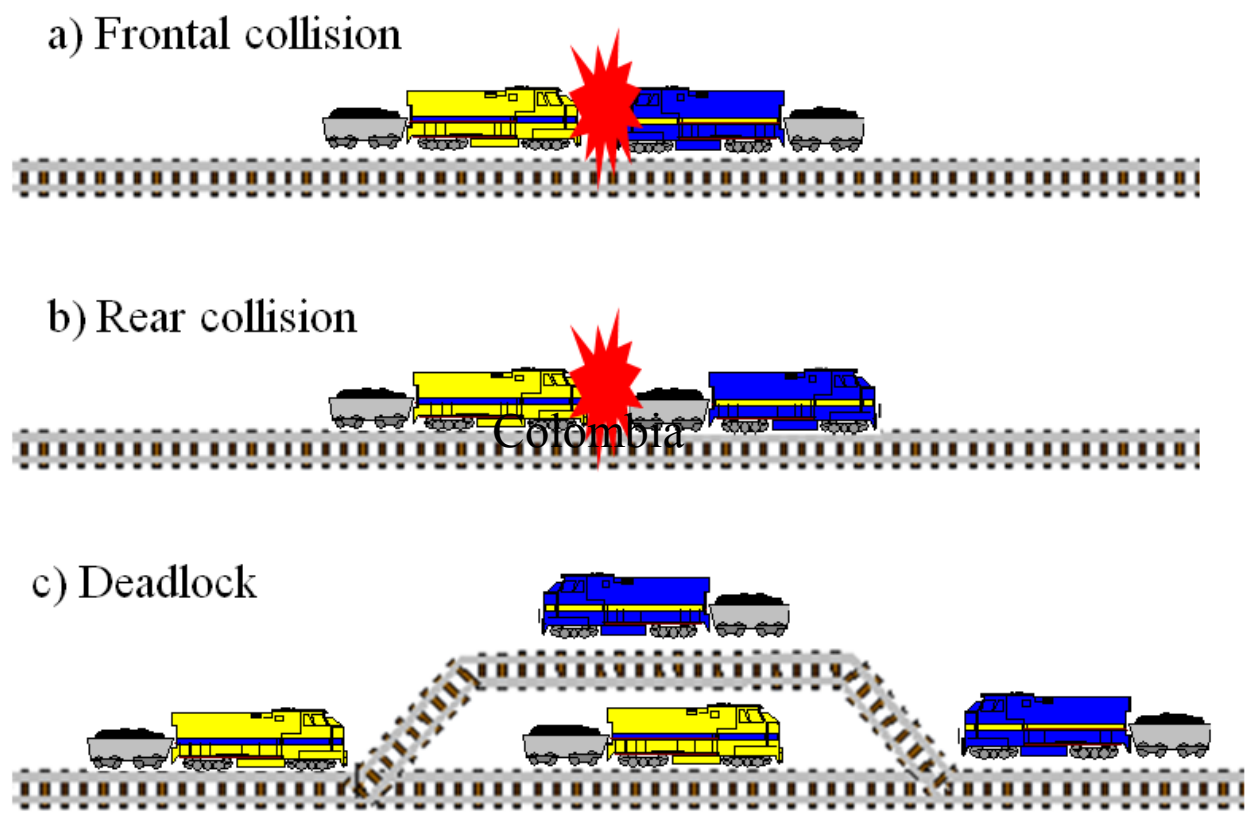

Figure 2: Situations that should be prevented in a railroad line.

The rules and actions taken to avoid these situations truly constrains the railroad capacity, and should be represented in simulation model. Without them, the simulation could easily perform better than the real line, leading to wrong decisions. Actually, the main focus of many simulation studies is to evaluate the infrastructure and traffic rules, looking for better ways to increase the line capacity. istics:

Cerrejón relies on a single railroad line connecting the mine to the port, with the following character-

- Single line with four sidings.

- Irregular traffic rules: in some areas the train can stop at the line between sidings, but in others, it is not allowed.

- When approaching the mine or the port, different rules apply involving specific states of these areas (like space in the coal yard, or empty lines to accommodate the train).

- The line is used by different trains with different movement prioritizations.

- The blockage sections at one direction are different from the ones at the opposite direction, for the same line.

- All trains are permanent, moving in a closed loop from mine to port, and vice-versa.

To address all these features, and avoiding the situations presented on Figure 2 at the same time, previous studies were searched to find an existing technique that fits on that problem. The work from Lewellen and Tumay (1998) focus on the operations happening in stations, like refueling, crew change or inspection, but the rail infrastructure is not detailed. In the study presented by Pater and Teunisse (1997), the lines are represented as "pipes", and the crossing points or obstacles represented as "nodes". However, the security system that should prevent situations "a" and " $b$ " is modeled with a high abstraction level. 
Previous studies from Paragon had focus on detailed railroad infrastructure: In Franzese et al. (2003), a railroad was modeled for iron ore cyclic trains, but running on a double line. The algorithm presented by Fioroni et al. (2005) and Fioroni and Botter (2008) shows a way to move a train along a single line, considering almost every situation for this line, but it is designed to work on a more uniform railroad, with the same type of signaling and rules for the entire network. All the movement intelligence and decision process, the movement algorithm, is "inside" the train. It moves towards a destination and may stop or move depending on what happens on the line ahead. They are "intelligent trains", and may be considered as "agents". Despite that, to make them work at the Cerrejón's line, that intelligence should be improved to support the differences along the line, which would be a very complex and long job since that intelligence is very complex already.

So, instead of using a large algorithm that works for the entire line, a set of much smaller algorithms were developed for each line section. This approach is described ahead.

\section{SIGNAL-ORIENTED APPROACH}

Since each line section required a different set of decisions, the model "intelligence" was moved from the train to the signaling system. In this approach, the train just knows its destination and the path towards that, and has to respect the signals along the line: green - advance in full speed, yellow - advance in low speed (train moving ahead) and red - full stop (train stopped in the next section).

The signals are responsible for avoiding conflicts and collisions on the line. Its implementation is very similar to a PLC programming, making the signal change its color based on the status of a set of "sensors". These sensors are categorical variables in the model's logic, that can change from zero (green) to two (red) when a train has just passed the signal, and from two to one (yellow) when the train has cleared the segment in front of the signal.

This is a very easy and intuitive way to model, but also has its drawbacks. It might be hard to apply on big networks, since the modeler has to "individually program" all signals on the line, writing particular expressions for every signal. This might be a strenuous work if there are too many signals on the line, each with different characteristics, or if the line has many branches that require special treatment regarding traffic. That is not the case for Cerrejón's line, with its four sidings and few branches.

Three different types of intelligence were handled by signals to determine their color, each depending on the complexity of the segment.

\subsection{Intelligence Type 1: Signals for Immediate Sections}

The first type of intelligence is simple, and applies to signals on the line that just need to check if one or two positions ahead are occupied by a train going on the same direction, as shown in Figure 2. In case that one position ahead is occupied the signal will take the value of 2: stop, train ahead. If a train is located two positions in front the signal will be seen as 1: slow down, caution train nearby. Figure 3 shows the schematic for this situation.

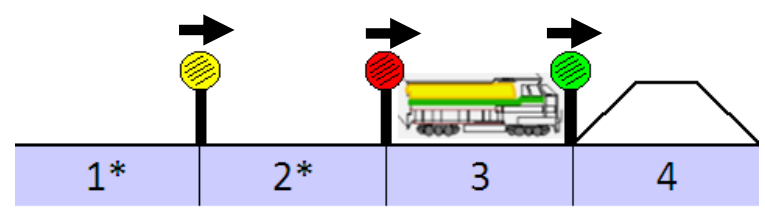

*Segments with first type of intelligence

Figure 3: Segments with first type of intelligence. 


\subsection{Intelligence Type 2: Siding Signal}

The second type of intelligence is used in more complex segments. These include sidings and inner bound segments of the loop used by trains to get into the railway. This type of intelligence uses the same logic of the first type but incorporates other model restrictions such as blockage of segments for trains moving in opposite direction as shown in Figure 4, and maximum capacity limitations, as shown in Figure 5.

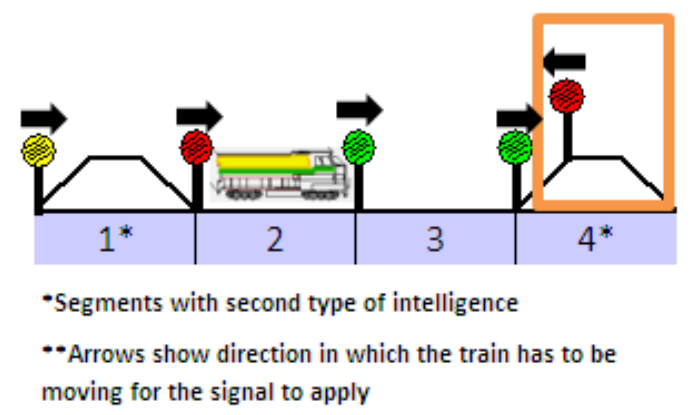

Figure 4: Segment blockage.

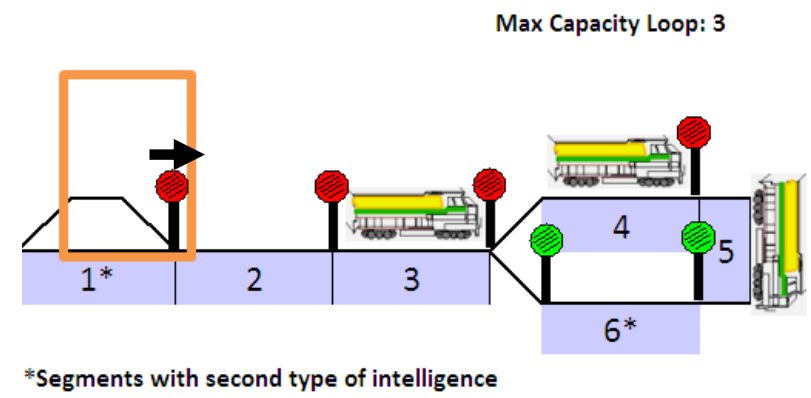

Figure 5: Maximum capacity (if a train in segment 1 moves to segment 2, the line could be blocked).

\subsection{Intelligence Type 3: Branch Signal}

The third type of intelligence works under the same principles of the first type but allows the signal to check two segments at a time to spot changes. This type of intelligence is mostly used when the train has to decide between two possible routes. If the two segments are being occupied, the signal changes to 2: stop train. Otherwise, if just one position is being occupied the signal will allow the train to go to the unoccupied segment as shown with Figure 6 below.

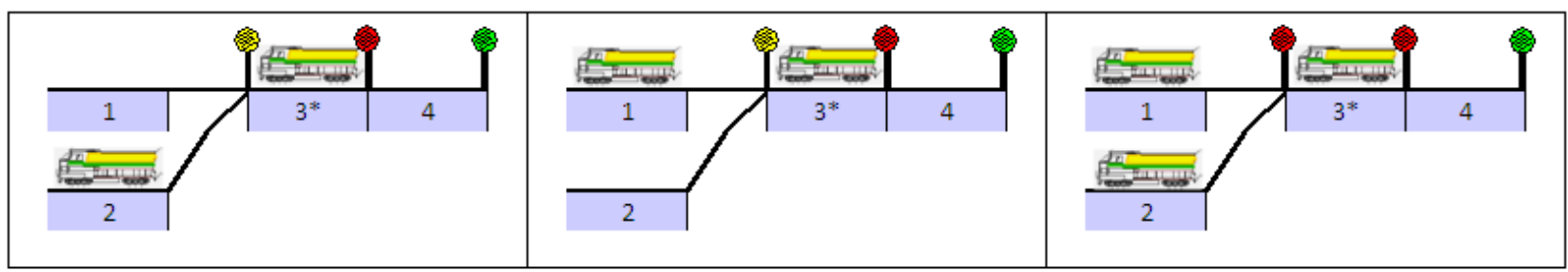

*Segments with third type of intelligence

Figure 6: Segments with third type of intelligence.

Every time that a train moves and alters the current state or any of the conditions of a segment, the signal guarding it will evaluate its conditions and in case it is needed, it will change its state. As in the second algorithm, the model is not evaluating all the conditions of the system. 


\section{THE MODEL}

The model was built in the Arena simulation package with an Excel spreadsheet as the user interface, shown in Figure 7. The interface can be used to mount the scenario to be simulated.

General Simulation Parameters

\begin{tabular}{|c|c|c|c|}
\hline Simulation run time (days) & 363 & Starting date of the simulation & 02/jan/11 6:30 \\
\hline & & $\begin{array}{l}\text { Write train complete hours } \\
\text { report }\end{array}$ & 1. No \\
\hline
\end{tabular}

\begin{tabular}{|l|l|}
\hline Model Parameters & 2. Expansion \\
\hline Supplies Train Entrance & 2. Independent Entrance \\
\hline Second Loop at Mine Active & 2. Yes \\
\hline Second TUS at Port Active & 2. Yes \\
\hline Double Track Cosinas + SIDING ADIC LOC 21 & 1. No \\
\hline Fourth S/R & 1. No \\
\hline Fifth S/R & 1. No \\
\hline Ship Loaders Natural Windows Active & 2. Yes \\
\hline
\end{tabular}

\begin{tabular}{|c|c|c|c|}
\hline & \multicolumn{3}{|c|}{ MANUAL CHANGES } \\
\hline & Actual & P40 & P60 \\
\hline Supplies Train Entrance & Through Loc. 22 & Independent Entrance & Independent Entrance \\
\hline Second Loop & NO & NO & YES \\
\hline Second TUS & NO & NO & YES \\
\hline Change in supplies tran cycle & 48 & 48 & 24 \\
\hline DEMAND UC & $36,040,000$ & $50,000,000$ & $80,000,000$ \\
\hline Truck arrival & 1.51 & 1.26 & $1.51 / 1.26$ \\
\hline PM Parameters & $\begin{array}{l}\text {-Railway: } \\
\text {-Wed.: Starts: 8am Duration: } 10 \mathrm{~h} \\
\text {-Thu.: Starts: 8am Duration: } 6 \mathrm{~h} \\
\text {-Main Plant: } \\
\text {-Wed.: Starts:6:30am Duration:18.5h } \\
\text {-Secondary Plant: } \\
\text {-Thu.: Starts:6:30am Duration:24h }\end{array}$ & $\begin{array}{l}\text {-Railway: } \\
\text {-Tue.: Starts: 6:30am Duration: } 14 \mathrm{~h} \\
\text {-Thu.: Starts: 6:30am Duration: } 6 \mathrm{~h} \\
\text {-Main Plant: } \\
\text {-Tue.: Starts:6:30am Duration:18.5h } \\
\text {-Secondary Plant: } \\
\text {-Thu.: Starts:6:30am Duration:24h }\end{array}$ & $\begin{array}{l}\text {-Railway: } \\
\text { - Tue.: Starts: 6:30am Duration: 10h } \\
\text {-Thu.: Starts: 6:30am Duration: } 10 \mathrm{~h} \\
\text {-Main Plant: } \\
\text {-Tue.: Starts:6:30am Duration:24h } \\
\text {-Secondary Plant: } \\
\text {-Wed.: Starts:6:30am Duration:24h } \\
\text {-Satellite Plant: } \\
\text {-Thu.: Starts:6:30am Duration:24h }\end{array}$ \\
\hline
\end{tabular}

Figure 7: Partial view of the input user interface.

The model has a basic animation for the railway line to allow the user to check the system behavior, as can be seen in Figure 8. In that figure, the red arrow indicates a train moving from left to right. The animation shows the correct signalization around it, with a red sign behind it and a yellow sign behind the red. The opposite side of the line shows a red sign for any train that could be eventually parked at the next crossing, preventing a collision.

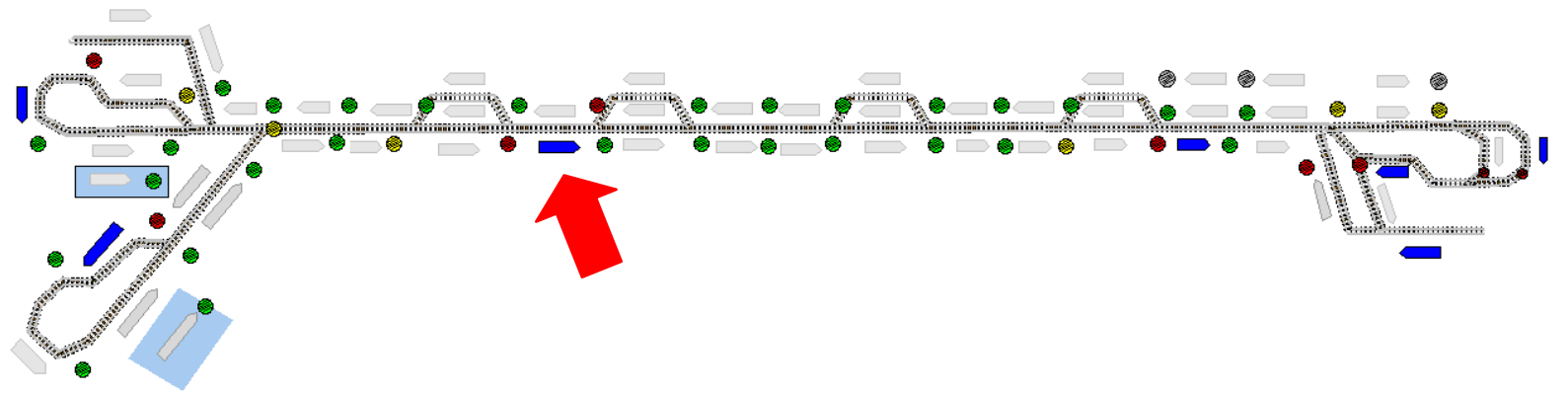

Figure 8: Model animation of railway line.

Additionally, there is an integrated animation used to control de entire process including the crushing plants, silos, railway line and port and which is also used to present the model to management. This animation is shown in Figure 9. 


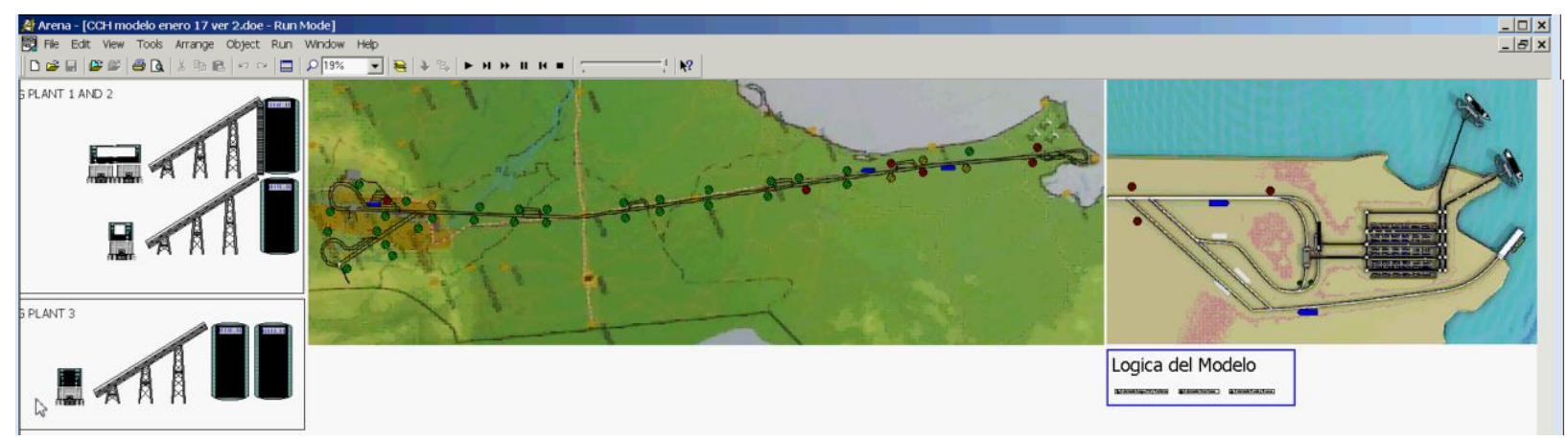

Figure 9: Integrated model animation.

\section{RESULTS}

Before using the simulation model to run forecasting scenarios, the model was validated with real operational data as shown in Figure 10 and Figure 11. The results shown in Figure 10 are specially important, because all of them are a direct result of the railroad behavior, like the train cycle. The proximity to the real data have confirmed that the adopted approach was really successful on representing Cerrejón's specific situations and requirements. The results at Figure 11 also confirms that other aspects of the system were also correctly represented in the model. Since the difference between simulation and real operational data was not significant, the model was then used in scenario analysis.

$\square$ Real Operational Data 2011 Simulation Model Data

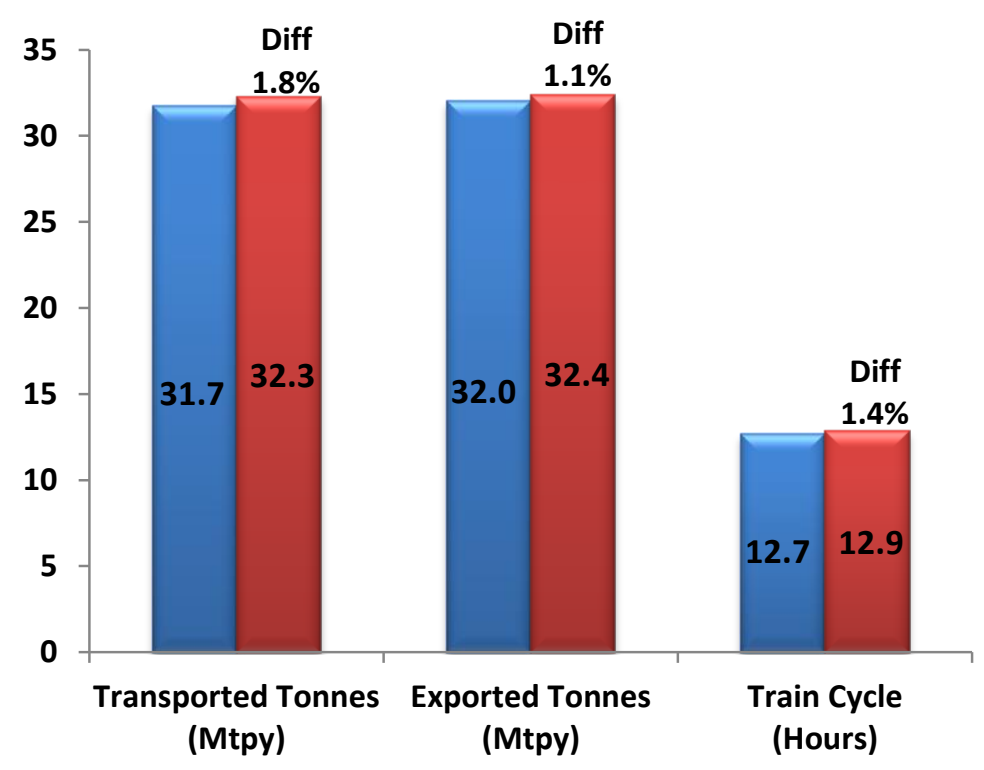

Figure 10: Model validation results. 


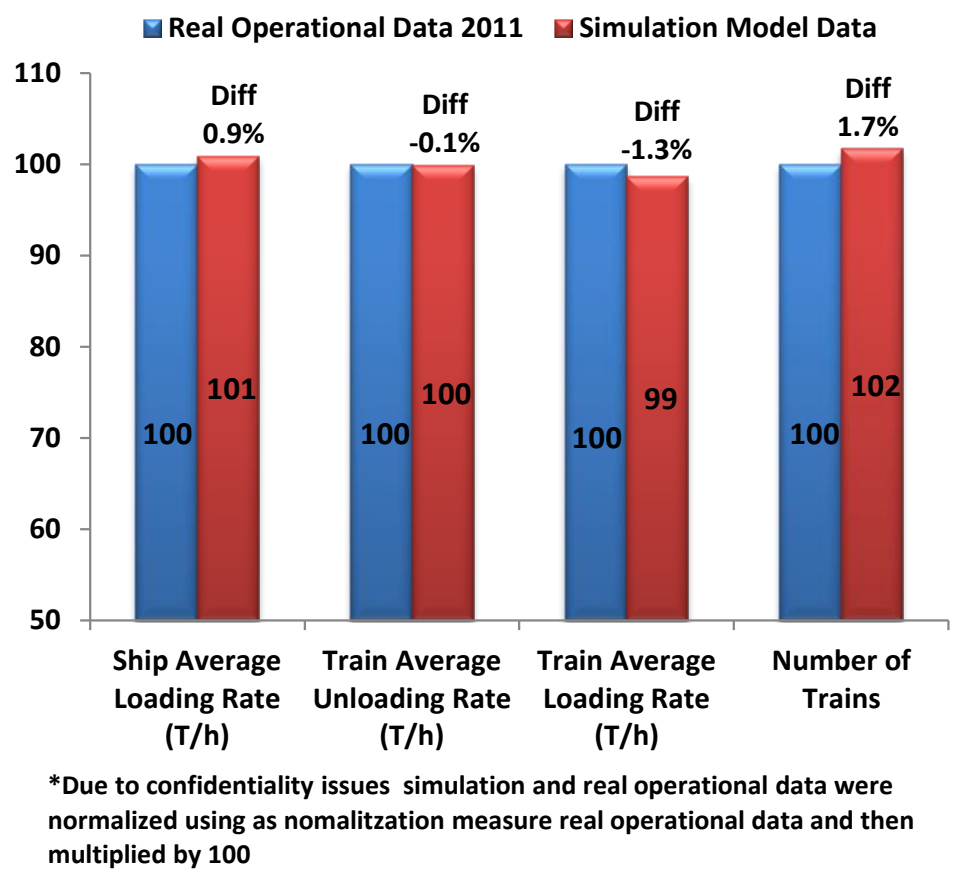

Figure 11: Model validation results.

With this tool on hand, Cerrejón did a series of experiments to set the guidelines for the expansion project that was under revision. The goal of the project was to achieve railroad transportation of $40 \mathrm{Mtpy}$ (million tons per year). Having in mind that at the time the capacity of the coal chain was of 32.3 Mtpy major investments had to be tested in order to achieve the desired throughput. Previous projects done by external advisors to improve the coal chain were taken into account and used as initial scope for the analysis. These included more coal cars per consist and a second ship loader that would increase the coal chain capacity to 38.5 Mtpy.

After analyzing the coal chain behavior two major bottlenecks were identified, these were related with train unloading and railway transportation. Various scenarios were run testing different number of coal cars per consist, number of consists, and different alternatives that would increase the train unloading rate. The best scenario proved to be the upgrade of one stacker reclaimer at port which had a lower stacking rate and longer consists than the ones that had been already recommended. The result of this scenario was 41.1 Mtpa as shown in Figure 12. 


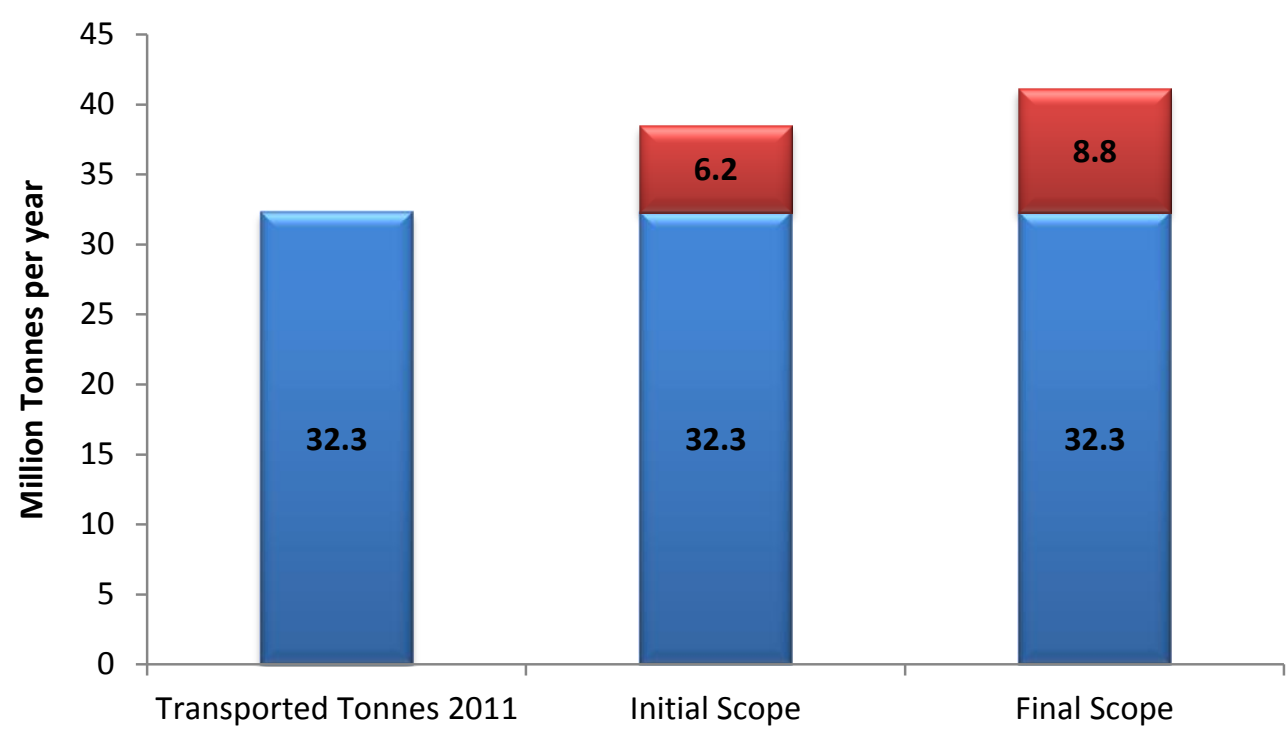

Figure 12: Incremental throughput.

\section{CONCLUSIONS}

The choice of developing a signal-oriented approach to model the railroad have proven extremely precise, fitting the real system KPIs with very small error levels. That allowed the Cerrejón's team to perform many experiments for future scenarios, even reaching the goal of 40 Mtpy.

The signal-oriented approach simplifies the modeling when new scenarios are required. Since the model decision rules are similar to the real system, automated or not, they are very easy to be implemented and checked by the train traffic personnel. It is also a very straightforward Arena model that is easy to follow and debug, which could be built also in other simulation languages.

Understanding the advantages and disadvantages of the different simulation approaches that can be used to model a railroad line is important, as there's not a "best approach" for all situations. The size of the network and the objective of the study should guide the decision.

For models that will be used for operational/tactical decisions, the signal-oriented approach allow to treat the logic of each signal differently and adapt to specific conditions of the operation. For more strategic models this might not be necessary and using a less detailed approach could be more appropriate.

Also, this study provided some teamwork insights. Working with a team that develops the models but with an advisor that helps in the design and peer review has proven very valuable. Combining the Cerrejón's knowledge of the business with that on simulation of Paragon has accelerated the modeling process and allowed the team to "think out of the box" to find new alternatives and approaches.

\section{ACKNOWLEDGMENTS}

The authors thanks Carbones de Cerrejón for supporting this project and for authorizing the use of its information for this paper.

\section{REFERENCES}

Dessouky, M. M., Q. Lu, and R. C. Leachman. 2002. "Using Simulation Modeling to Assess Rail Track Infrastructure in Densely trafficked Metropolitan Areas." In Proceedings of the 2002 Winter Simulation Conference, edited by E. Yücesan, C.-H. Chen, J. L. Snowdon, and J. M. Charnes, 725-731. 
Franzese, L. A. G., M. M. Fioroni, and R. C. Botter. 2003. "Railroad Simulator on Closed Loop" In Proceedings of the 2003 Winter Simulation Conference, edited by S. Chick, P. J. Sánchez, D. Ferrin and D. J. Morrice, 1602-1606. Piscataway, New Jersey: Institute of Electrical and Electronics Engineers, Inc.

Fioroni, M. M., L. A. G. Franzese, R. C. Botter, N. Y. H. Pereira, and M. N. Machado. 2005. "Railroad Infrastructure Simulator" In Proceedings of the 2005 Winter Simulation Conference, Edited by M. E. Kuhl, N. M. Steiger, F. B. Armstrong, and J. A. Joines, 2581-2584. Piscataway, New Jersey: Institute of Electrical and Electronics Engineers, Inc.

Fioroni, M. M., and R. C. Botter. 2005. “An Algorithm for Train Movement Simulation” In Proceedings of the 2005 International Conference on Industrial Logistics ICIL, Montevideo, Uruguay.

Fioroni, M. M., and R. C. Botter. 2008. "Simulação em ciclo fechado de malhas ferroviárias e suas aplicações no Brasil: avaliação de alternativas para o direcionamento de composições." Ph.D. thesis, Departamento de Engenharia Naval, Faculdade Politécnica - Universidade de São Paulo. http://www.teses.usp.br/teses/disponiveis/3/3135/tde-03062008-180002/pt-br.php [Accessed April 5, 2012].

Fioroni, M. M., R. C. Botter, F. M. Pompermayer, and L. A. G. Franzese. 2004. "Estudo Estratégico de Dimensionamento da Infra-Estrutura do Pátio Ferroviário de Tubarão Através de Simulação" In Proceedings of the XVII ANPET, http://www.cbtu.gov.br/estudos/pesquisa/anpet_xviiiCongrpesqens/ac/arq87.pdf [Accessed April 5, 2013]. Florianópolis-SC, Brazil.

Hooghiemstra, J. S., and M. J. G. Teunisse. 1998. "The Use of Simulation in The Planning of the Dutch Railway Services" In Proceedings of the 1998 Winter Simulation Conference, Edited by D. J. Medeiros, E. F. Watson, J. S. Carson and M. S. Manivannan, 1139-1145. Piscataway, New Jersey: Institute of Electrical and Electronics Engineers, Inc.

Krueger, H., E. Vaillancourt, S. J. Vucko, A. M. Drummie, and J. Bekavac. 2000. "Simulation Within the Railroad Environment" In Proceedings of the 2000 Winter Simulation Conference, Edited by J. A. Joines, R. R. Barton, K. Kang, and P. A. Fishwick, 1191-1200. Piscataway, New Jersey: Institute of Electrical and Electronics Engineers, Inc.

Leilich, R. H. 1998. "Application of Simulation Models in Capacity Constrained Rail Corridors" In Proceedings of the 1998 Winter Simulation Conference, Edited by D. J. Medeiros, E. F. Watson, J. S. Carson and M. S. Manivannan, 1125-1133. Piscataway, New Jersey: Institute of Electrical and Electronics Engineers, Inc.

Lewellen, M., and K. Tumay. 1998. "Network Simulation of a Major Railroad" In Proceedings of the 1998 Winter Simulation Conference, Edited by D. J. Medeiros, E. F. Watson, J. S. Carson and M. S. Manivannan, 1135-1138. Piscataway, New Jersey: Institute of Electrical and Electronics Engineers, Inc.

Pater, A. J. G., and M. J. G. Teunisse. 1997. "The Use of a Template-Based Methodology in the Simulation of a New Cargo Track from Rotterdam Harbor to Germany" In Proceedings of the 1997 Winter Simulation Conference, Edited by S. Andradóttir, K. J. Healy, D. H. Withers, and B. L. Nelson, 1176-1180. Piscataway, New Jersey: Institute of Electrical and Electronics Engineers, Inc.

\section{AUTHOR BIOGRAPHIES}

MARCELO MORETTI FIORONI is a senior simulation consultant with an Electrical Engineering degree, MSc. in Manufacturing and PhD in Logistics at University of São Paulo (USP). Has participated in hundreds of successful projects with simulation. Co-founder of PARAGON Decision Science in 1992, the pioneer and leading simulation consulting company in South America. Teaches Simulation at Faculdades Metropolitanas Unidas (FMU) in São Paulo, Brazil. Has trained more than 1,200 professionals in simulation. He can be contacted by email atmarcelo@paragon.com.br. 
DANIEL CUERVO is an Industrial Engineer from Universidad de los Andes in Colombia, and an MBA from London Business School. He works for Cerrejon where he is head of the Business Intelligence Division. He has worked as a business consultant in applied mathematical modeling. His email address is daniel.cuervo@cerrejoncoal.com.

PAOLA SANCHEZ is an Industrial Engineer from Universidad de los Andes in Colombia with an MSc. in Industrial Engineering with focus in Operations Research and Statistics from the same university. She works for Cerrejon as an analyst for the Business Intelligence Division. She has experience in data analysis and systems simulation. She can be contacted by email at paola.sanchez@cerrejoncoal.com.

ISAC REIS DE SANTANA is a simulation consultant. With Technical Degree, he has participated in almost 30 successful projects with simulation and teaches simulation in Paragon. He can be contacted by email atisac@paragon.com.br.

JOHANNA GÓMEZ QUEVEDO is a simulation consultant with a Production Engineering degree, an MSc. in Production Management from the Pontificia Universidade Católica do Rio de Janeiro (PUC). She has participated in different projects involving simulation as Consultant at PARAGON Decision Science, the pioneer and leading simulation consulting company in South America. She can be contacted by email atjohanna@paragon.com.br.

LUIZ AUGUSTO G. FRANZESE is a senior simulation consultant with a Production Engineering degree and MSc. in Logistics, who has completed hundreds of projects with simulation. Founded PARAGON Decision Science in 1992, the pioneer and leading simulation consulting company in South America. Has trained more than 1,200 professionals in simulation. He can be contacted by email at augusto@paragon.com.br.

FRANCESCO NARDUCCI is an Industrial Engineer from Universidad del Norte in Colombia with an MSc. in Industrial Engineering from the same university. He works for Cerrejon as an analyst for the Business Intelligence Division developing simulation models and providing support for optimization tools. He taught Simulation at Universidad del Norte. He can be contacted by email at francesco.narducci@cerrejoncoal.com. 